\title{
Pengaruh Kepemimpinan Kepala Sekolah, Supervisi Pendidikan dan Budaya Sekolah Terhadap Kinerja Guru Sekolah Dasar Negeri
}

\author{
Cepi Safruddin Abdul Jabar'1, Tri Joko Susilo \\ ${ }^{1}$ Universitas Negeri Yogyakarta, Yogyakarta, DIY, Indonesia \\ ${ }^{2}$ SD Negeri Kajoran 2 Magelang, Magelang, Jawa Tengah, Indonesia
}

Corresponding author: Cepi Safruddin Abdul Jabar (e-mail: cepi_safruddin@uny.ac.id)

\begin{abstract}
Abstrak: Penelitian ini bertujuan untuk mengetahui pengaruh kepemimpinan kepala sekolah, supervisi pendidikan dan buday a sekolah terhadap kinerja guru. Lokasi penelitian yaitu sekolah dasar negeri (SDN) di Kecamatan Kajoran Kabupaten Magelang. Penelitian ini menggu nakan pendekatan kuantitatif. 144 guru dipilih sebagai sampel penelitian dengan teknik area proportionate random sampling. Pengumpulan data menggunakan kuesioner. Pengujian hipotesis menggunakan rumus regresi sederhana dan ganda. Hasil penelitian menunjukkan terdapat pengaruh yang positif dan signifikan antara kepemimpinan kepala sekolah, supervisi pendidikan dan budaya sekolah terhadap kinerja guru secara sendiri-sendiri atau bersamasama. Implikasinya yaitu peningkatan kinerja guru perlu memperhatikan ketiga variabel yang mempengaruhi tersebut.
\end{abstract}

Kata kunci: kepemimpinan kepala sekolah, supervisi pendidikan, budaya sekolah, kinerja guru

\section{The Effect of Principal Leadership, Educational Supervision, and School Culture on Work Performance of Teachers at Public Elementary Schools}

\begin{abstract}
This study aims to determine the influence of principal leadership, educational supervision, and school culture on teacher performance. The research was conducted in public elementary schools in Kajoran Subdistrict, Magelang. This research used a quantitative approach. 144 teachers were selected as a sample using proportional random sampling area technique. Valid and reliable questionnaires were developed to collect data. The simple regression and multi regression technique were used to analyze data. The findings show a positive and significant influence of the principal leadership, educational supervision, and school culture on teacher performance individually or simultaneously. The implication of this study is that in order to improve the teachers ' performance, the three influencing factors should be considered.
\end{abstract}

Keywords: principal leadership, educational supervision, school culture, teacher performance 


\section{PENDAHULUAN}

Mutu pendidikan dipengaruhi oleh berbagai faktor salah satunya, kualitas guru. Guru merupakan ujung tombak sebuah sistem pendidikan yang berperan penting dalam mewujudkan tujuan pendidikan nasional. Guru berinteraksi langsung dengan siswa sehingga dapat disimpulkan bahwa guru merupakan salah satu faktor penentu keberhasilan pendidikan. Hal inilah yang membuat segala aspek peningkatan mutu pendidikan selalu bermuara pada guru (Fajriah, 2017). Untuk menjalankan peranannya, guru dituntut mampu memberikan dan merealisasikan harapan dan keinginan semua pihak terutama masyarakat dalam membina anak didik (Mammaova: 2019, Darling-Hammond, 2000).

Terdapat guru di Kecamatan Kajoran, Kabupaten Magelang yang belum professional. Mereka juga belum mempunyai sertifikat pendidik. Kinerja mereka belum maksimal (Supraswati, 2016). Contohnya guru belum menggunakan mediapembelajaran atau alat peraga dalam proses pembelajaran untuk meningkatkan pemahaman belajar pada anak (Nasriyah, 2014). Ceramah tanpa alat peraga masih menjadi metode "unggulan" guru.

Kepala sekolah sebagai pemimpin di sekolah hendaknya mampu meningkatkan kinerja guru. Kepala sekolah hendakmya mampu menjadi teladan bagi guru, memiliki integritas dan juga kemampuan profesional. Namun, beberapa kepala sekolah kurang memiliki motivasi, semangat, dan kedisiplinan dalam melaksanakan tugas. Tidak jarang, beberapa kepala sekolah datang terlambat (Latief, 2016). Selain itu, pemahaman kepala sekolah tentang berbagai masalah dan tantangan pada era globalisasi masih kurang (Oktradiksa \& Nugroho, 2015).

Kepala sekolah hendaknya mampu memberdayakan potensi dan sumber daya di sekolah, utamanya guru. Mereka hendaknya mampu menguasai perkembangan ilmu pengetahuan dan teknologi. Kepala sekolah sebagai pemimpin harus mampu mempengaruhi guru-guru untuk bekerja seperti yang diharapkan. Terdapat berbagai cara yang dapat dilakukan kepala sekolah untuk meningkatkan kinerja guru, salah satunya supervisi.supervisi pendidikan sangat berpengaruh untuk menciptakan pelayanan pendidikan, pembelajaran pendidik, dan tenaga kependidikan yang bermutu. Supervisi adalah segala bantuan dari supervisor untuk memperbaiki manajemen sekolah dan meningkatkan kerja staf/guru dalam menjalankan tugas, fungsi, dan kewajibannya sehingga tujuan pendidikan akan tercapai dengan optimal, (Jasmin \& Mustofa, 2013). Seorang kepala sekolah harus dapat memberikan saran dan bimbingan kepada guru.

Berdasarkan studi pendahuluan di Kecamatan Kajoran, Kabupaten Magelang, terdapat beberapa masalah yang dihadapi sekolah seperti kepala sekolah belum membuat program 
supervisi dan pelaksanaan supervisi yang kurang berkesinambungan Akibatnya, evaluasi proses pembelajaran belum maksimal. Ketidakmampuan kepala sekolah melaksanakan supervisi membuat kepala sekolah kurang memahami kondisi guru. Buktisupervisi pendidikan akan dibukukan dalam dokumen guru seperti buku tamu kelas, buku supervisi guru, dan program supervisi.

Kemampuan kepala sekolah melaksanakan supervisi sangat penting untuk perbaikan pembelajaran dan layanan pendidikan. Permendiknas Nomor 13 Tahun 2007 Tentang Standar Kepala Sekolah menyebutkan bahwa seorang kepala sekolah dituntut untuk mampu mengatur agar seluruh potensi sekolah berfungsi secara optimal. Pemimpin yang efektif dan efisien adalah pemimpin yang mampu memahami keahlian masing-masing bawahannya. Pemahaman tentang potensi yang dimiliki masing-masing guru akan memudahkan kepala sekolah dalam menerapkan kebijakan dan pendelegasian tugas sesuai dengan kemampuan masing-masing secara adil dan merata. Hal ini akan sangat mendukung terciptanya budaya sekolah yang nyaman dan kondusif.

Budaya sekolah yang kondusif dapat mempengaruhi kinerja guru di sekolah. Budaya sekolah merupakan serangkaian norma, nilai, tradisi, dan kepercayaan yang didukung dan menjadi ciri khas sekolah, mendukung suasana kerja serta memunculkan nilai-nilai positif yang menjadi pembiasaan guru dan siswa dalam berperilaku positif di sekolah. Berdasarkan studi pendahuluan di beberapa sekolah yang menjadi objek penelitian masih terdapat kepala sekolah yang belum mampu menciptakan budaya sekolah kondusif untuk meningkatkan kinerja guru. Hal ini terlihat dari budaya sekolah yang kurang baik misalnya guru belum disiplin dari sisi waktu, guru datang terlambat di sekolah, guru pulang sebelum waktu yang ditentukan, guru belum taat aturan atau patuh hanya ketika kepala sekolah ada. Kondisi tersebut tentu akan sangat mempengaruhi kinerja guru di sekolah.

Berdasarkan uraian di atas dapat disimpulkan bahwa mutu sekolah menjadi tanggung jawab bersama antara kepala sekolah dan guru. Kinerja guru merupakan tolak ukur kualitas layanan pendidikan dalam suatu penyelenggara pendidikan. Kepemimpinan kepala sekolah yang baik, supervisi yang berkesinambungan, dan budaya sekolah yang kondusif, secara simultan dibutuhkan untuk meningkatkan kinerja guru.

Kinerja menurut Longman Dictionary dalam Wibowo (2011:23) yaitu "the ability of a person or machine to do something well'. Kinerja atau prestasi kerja (performance) diartikan sebagai ungkapan kemampuan yang didasari oleh pengetahuan, sikap, ketrampilan dan motivasi dalam menghasilkan sesuatu. Parameter yang paling umum digunakan untuk 
mengukurnya adalah efektivitas, efisiensi, dan produktivitas. Mangkunegara (2009: 67) menyatakan bahwa kinerja adalah "hasil kerja secara kualitas dan kuantitas yang dicapai oleh seorang pegawai dalam melaksanakan tugasnya sesuai tanggung jawab yang diberikan kepadanya". Oleh karena itu, dapat disimpulkan bahwa kinerja merupakan suatu hasil atau prestasi kerja dari kemampuan seseorang dalam menjalankan pekerjaan yang ditekuninya sesuai dengan ketentuan atau ketetapan yang berlaku dalam sebuah organisasi.

Wirawan (2013, p. 532) menyatakan "kepemimpinan pendidikan adalah proses pemimpin pendidikan mempengaruhi peserta didik dan pemangku kepentingan pendidikan serta menciptakan sinergi untuk mencapai tujuan pendidikan. Kepemimpinan kepala sekolah merupakan hal yang utama dalam memajukan sekolah. Wahjosumidjo (2010: 83) menyatakan bahwa "kepala sekolah sebagai seorang tenaga fungsional guru yang diberi tugas untuk memimpin suatu sekolah di mana diselenggarakan proses belajar mengajar, atau tempat di mana terjadi interaksi antara guru yang memberi pelajaran dan murid yang menerima pelajaran”. Oleh karena itu, kepemimpinan kepala sekolah adalah proses memengaruhi, menggerakkan, memberikan motivasi, dan mengarahkan orang-orang yang ada dalam sekolah untuk mencapai tujuan sekolah. Dengan demikian kepala sekolah bertanggung jawab untuk menciptakan lingkungan sekolah, sebagai wakil organisasi kepala sekolah harus senantiasa dapat dipercaya dan mempunyai integritas yang tinggi.

Selanjutnya, untuk menjamin kualitas layanan belajar, supervisi kepada guru oleh kepala sekolah merupakan hal yang penting. Wiles (Sagala, 2013:195) mengemukan bahwa supervisi pendidikan merupakan bantuan pengembangan dan peningkatan situasi pembelajaran yang lebih baik. Purwanto (2009: 76) menyatakan "supervisi ialah suatu aktivitas pembinaan yang direncanakan untuk membantu para guru dan pegawai sekolah lainnya dalam melakukan pekerjaan mereka secara efektif." Jadi, supervisi pendidikan adalah bantuan berupa pembinaan dan bimbingan profesional kepada guru-guru dari seorang ahli/profesional.

Selain kepemimpinan dan supervisi, budaya sekolah juga tidak dapat terpisahkan dari kegiatan- kegiatan sekolah. Wirawan (2008: 10) mendefinisikan budaya organisasi sebagai norma, nilai-nilai, asumsi, kepercayaan, falsafat, kebiasaan organisasi, dan sebagainya (isi budaya organisasi). Budaya ini dikembangkan dalam waktu yang lama oleh pendiri, pemimpin, dan anggota organisasi yang disosialisasikan dan diajarkan kepada anggota baru serta diterapkan dalam aktivitas organisasi sehingga mempengaruhi pola pikir, sikap, dan perilaku anggota organisasi dalam memproduksi produk, melayani para konsumen, dan mencapai tujuan organisasi. 
Deal \& Peterson (1999) mengemukakan "school culture is the set of norms, value, believe, ritual, ceremonies, and symbol that make up the personal of the school." Artinya, budaya sekolah merupakan serangkaian norma-norma, nilai-nilai, kepercayaan-kepercayaan, ritual, upacara-upacara dan simbol-simbol yang dilaksanakan oleh seluruh warga sekolah. Sekolah dengan budaya positif mempunyai serangkaian nilai yang mendukung perilaku positif dimana siswa menaati norma dan aturan sekolah sehingga terwujud organisasi belajar yang kondusif. Sebaliknya, budaya sekolah yang negatif akan sering menimbulkan konflik yang dimulai dengan ketidakpercayaan, kesalahpahaman antara siswa dengan siswa, guru dengan guru, guru dengan siswa, guru dengan kepala sekolah dan siswa dengan kepala sekolah. Dengan demikian, budaya sekolah merupakan serangkaian norma, nilai, keyakinan, filsafah dan kebiasaan yang dianut oleh seluruh warga sekolah yang menjadi ciri khas suatu sekolah. Budaya sekolah mendukung suasana kerja dan memunculkan nilai-nilai positif yang akhimya menjadi pembiasaan guru dan siswa dalam berperilaku positif di sekolah.

\section{METODE PENELITIAN}

Penelitian ini menggunakan pendekatan kuantitatif dengan jenis penelitian korelasional. Penelitian dilakukan di 29 sekolah dasar negeri (SDN) di Kecamatan Kajoran, Kabupaten Magelang. Waktu pelaksanaannya bulan April sampai dengan Agustus 2017. Populasi penelitian ini yaitu seluruh guru SDN di Kecamatan Kajoran Kabupaten Magelang dengan jumlah 224 guru.

Teknik sampling yang digunakan dalam penelitian ini adalah teknik area proporsional random sampling. Penentuan besaran sampel populasi mengacu pada rumus Slovin. Hasilnya yaitu besaran sampel sejumlah 144 guru. Jumlah sampel tersebut kemudian diambil dari tiga area, yaitu area Daerah Binaan (Dabin) 150 sampel, area Dabin 248 sampel, area Dabin 346 sampel. Metode pengumpulan data menggunakan kuesioner yang pengukurannya menggunakan skala sikap. Data yang diperoleh berupa angka kemudian ditafsirkan secara kualitatif. Kuesioner dibuat dalam bentuk tertutup dengan empat pilihan (option), selalu $=4$, sering= 3, kadang-kadang $=2$, dan, tidak pernah=1 (Sugiyono, 2010).

Validitas instrumen dilakukan dengan expert judgement dan uji coba. Hasilnya, dilakukan perbaikan terhadap beberapa item pada variabel. Pengujian validitas menggunakan korelasi product moment yang dikemukanan oleh Pearson. Nilai reliabilitas penelitian ini menggunakan Alpha-Cronbach. Instrumen dikatakan reliabel jika nilai Alpha Cronbach >0,60. Hasil reliabilitas masing-masing instrumen yaitu 0,886 untuk variabel kepemimpinan kepala sekolah, 0,944 untuk variabel supervisi pendidikan, 0,866 untuk variabel budaya sekolah, dan 
0,919 untuk variabel kinerja guru. Analisis data penelitian menggunakan analisis deskriptif untuk menjawab permasalahan secara deskriptif. Untuk menghitung skor ideal digunakan rumus sebagai berikut:

Skor ideal $=$ skor tertinggi $\mathrm{x}$ jumlah item/butir $\mathrm{x}$ jumlah responden

$\%$ Ketercapaian $=($ jumlah skor hasil penelitian/ skor ideal $) \times 100 \%$

Selanjutnya, pengujian normalitas dilakukan untuk mengetahui persebaran data, apakah terdistribudi normal atau tidak. Pengujian ini dilakukan dengan menggunakan statistik kolmogorov-smirnov dengan bantuan SPSS 23. Data dikatakan terdistribusi normal jika hasil uji normalitas pada asymptotic significance $\geq 0,05$. Data hasil pengujian hipotesis dapat dilihat pada Tabel. 1

Tabel1.Hasil ujinormalitas

\begin{tabular}{llll}
\hline No. & Variabel yang diukur & Nilai normalitas & Ket. \\
\hline 1. & Kepemimpinan kepala sekolah & 0,086 & Terdistribusi Nomal \\
2. & Supervisi kepala sekolah & 0,200 & Terdistribusi Nomal \\
3. & Budaya sekolah & 0,069 & Terdistribusi Nomal \\
4. & Kinerja Guru & 0,200 & Terdistribusi Nomal \\
\hline
\end{tabular}

Pengujian linieritas diperlukan untuk mengetahui apakah dua variabel secara signifikan mempunyai hubungan yang linier atau tidak. Pengujian dilakukan sendiri-sendiri antara variabel X dengan variabel Y. Hubungan kedua variabel dikatakan linier jika linearity $<0,05$ dan Deviaty from Linearity > 0,05. Hasil pengujian linieritas dapat dilihat pada Tabel 2.

Tabel 2 Hasiluji linieritas

\begin{tabular}{lllll}
\hline No. & $\begin{array}{l}\text { Variabel yang } \\
\text { diukur }\end{array}$ & $\begin{array}{l}\text { Nilai } \\
\text { linerity }\end{array}$ & $\begin{array}{l}\text { Nilai deviaty } \\
\text { from linerity }\end{array}$ & $\begin{array}{l}\text { Hubungan 2 } \\
\text { variabel }\end{array}$ \\
\hline 1. & $\mathrm{X}_{1}-\mathrm{Y}$ & 0,000 & 0,571 & Linier \\
2. & $\mathrm{X}_{2}-\mathrm{Y}$ & 0,000 & 0,377 & Linier \\
3. & $\mathrm{X}_{3}-\mathrm{Y}$ & 0,000 & 0,800 & Linier \\
\hline
\end{tabular}

Multikolinearitas adalah keadaan di mana terjadi hubungan linier yang sempurna atau mendekati sempurna antarvariabel bebas dalam model regresi. Pengujian multikolinieritas menunjukan tidak ada hubungan kelinieran antar varibel bebas jika nilai toleransi $>0,10$ dan nilai VIF < 10. Hasil pengujian disajikan pada tabel 3.

Tabel3. Hasil uji multikolinieritas

\begin{tabular}{lllll}
\hline No & Variabel yang diukur & Nilai toleransi & Nilai VIF & Ket. \\
\hline 1. & Kepemimpian kepala sekolah & 0,655 & 1,527 & Tidak terjadimultikolinieritas \\
2. & Supervisi kepala sekolah & 0,720 & 1,389 & Tidak terjadi multikolinieritas \\
3. & Budaya sekolah & 0,851 & 1,175 & Tidak terjadi multikolinieritas \\
\hline
\end{tabular}


Heteroskedisitas adalah keadaan dimana terjadi ketidaksamaan varian dari residual untuk semua pengamatan pada model regresi. Pengujian dilakukan dengan uji Glejser. Variabel bebas dikatakan tidak mengandung heteroskeditisitas apabila probabilitas signfikasinya $>5 \%$. Hasil uji heteroskedisitas dapat dilihat pada Tabel 4.

Tabel4. Hasil uji heteroskedasitas

\begin{tabular}{clcc}
\hline No & Variabel yang diukur & Nilai signifikasi & Ket. \\
\hline 1. & Kepemimpinan KS & 0,510 & Tidak terjadiheteroskedastisitas \\
2. & Supervisi KS & 0,317 & Tidak terjadi heteroskedastisitas \\
3. & Budaya Sekolah & 0,089 & Tidak terjadi heteroskedastisitas \\
\hline
\end{tabular}

\section{HASIL}

Penelitian ini menggunakan regresi sederhana untuk menguji pengaruh masing-masing variabel bebas terhadap variabel terikat dan menggunakan uji regresi ganda untuk ketiga variabel bebas secara bersama-sama terhadap variabel terikat. Dalam uji regresi ini diketahui besarnya koefisien korelasi yang menunjukkan besaran hubungan antara variabel bebas dan terikat, koefisien determinasi yang menunjukkan besaran pengaruh variabel bebas terhadap variabel terikat dan persamaan regresi yang menunjukkan prediksi pengaruh perubahan variabel bebas terhadap variabel terikat.

\subsection{Pengaruh kepemimpinan kepala sekolah terhadap kinerja guru}

Uji hipotesis pertama menggunakan regresi sederhana antar variabel kepemimpinan (X1) dan kinerja guru (Y). Ha -nya yaitu kepemimpinan kepala sekolah berpengaruh kuat terhadap kinerja guru. Kriteria yang digunakan adalah Ha diterima jika nilai sign < 0,05. Hasil uji signifikasi dengan SPSS 23 dapat dilihat pada Tabel 6.

Tabel5. Hasil uji regresi linier X1 terhadap Y

\begin{tabular}{ccc}
\hline $\mathbf{R}$ & R Square & Adjusted R Square \\
\hline 0,591 & 0,350 & 0,345 \\
\hline
\end{tabular}

Tabel 6 menunukkan nilai $\mathrm{R}$ adalah 0,591. Artinya, terdapat korelasi antara X1 dan Y. Koefisien determinasi $\left(\mathrm{R}^{2}\right)$ sebesar 0,350 . Hal ini menunjukkan bahwa X1 berpengaruh terhadap Y sebesar 35\%. Artinya, kepemimpinan kepala sekolah berpengaruh terhadap kinerja guru sebesar 35\%. Analisis persamaan regresi antara X1 dan Y menggunakan rumus:

$$
\hat{Y}=56,055+0,591 X_{1}
$$

Persamaan regresi ini memiliki makna yaitu koefisien regresi atau nilai b sebesar 0,591. Artinya yaitu kenaikan satu skor supervisi pengawas akan meningkatkan skor kinerja guru 
sebesar 0,591. Ini juga bermakna semakin bertambah nilai kepemimpinan kepala sekolah $\left(\mathrm{X}_{1}\right)$, maka semakin bertambah pula nilai kinerja guru (Y).

\subsection{Pengaruh supervisi pendidikan terhadap kinerja guru}

Uji hipotesis kedua menggunakan regresi sederhana antar variabel supervisi pendidikan (X2) dan kinerja guru (Y). Hipotesisnya (Ha) yaitu supervisi pendidikan berpengaruh terhadap kinerja guru. Kriteria yang digunakan yaitu Ha diterima jika nilai sign < 0,05. Hasil uji signifikasi dengan SPSS 23 disajikan pada tabel 7.

Tabel7. Hasil ujiregresi linier X2 terhadap Y

\begin{tabular}{lll}
\hline R & R Square & Adjusted R Square \\
\hline 0,360 & 0,130 & 0,123 \\
\hline
\end{tabular}

Tabel 7 menunjukkan bahwa besarnya $\mathrm{R}$ adalah 0,360. Artinya, terdapat korelasi antara X2 dan Y. Koefisien determinasi $\left(\mathrm{R}^{2}\right)$ sebesar 0,130 menunjukkan bahwa X2 berpengaruh terhadap Y sebesar $13 \%$. Artinya yaitu kepemimpinan kepala sekolah berpengaruh terhadap kinerja guru sebesar 13\%. Analisis persamaan regresi antara X2 dan $\mathrm{Y}$ diperoleh dari persamaan berikut ini.

$$
\hat{\mathrm{Y}}=72,738+0,360 \mathrm{X}_{2}
$$

Persamaan regresi ini memiliki makna yaitu koefisien regresi atau nilai b sebesar 0,360. Artinya kenaikan satu skor kepemimpinan kepala sekolah akan meningkatkan skor kinerja guru sebesar 0,360. Ini juga bermakna semakin bertambah nilai supervisi pendidikan $\left(\mathrm{X}_{1}\right)$, maka semakin bertambah pula nilai kinerja guru $(\mathrm{Y})$.

\subsection{Pengaruh budaya sekolah terhadap kinerja guru}

Uji hipotesis ketiga menggunakan regresi sederhana antara variabel budaya sekolah (X3) terhadap kinerja guru (Y). Hipotesisnya (Ha) yaitu budaya sekolah berpengaruh terhadap kinerja guru. Kriteria yang digunakan adalah Ha diterima jika nilai sign $<0,05$. Hasil uji signifikasi dengan SPSS 23 dapat dilihat pada Tabel 8.

Tabel 8. Hasil uji regresilinier X3 terhadap Y

\begin{tabular}{lll}
\hline R & R Square & Adjusted R square \\
\hline 0,543 & 0,294 & 0,289 \\
\hline
\end{tabular}

Tabel 8 menunjukkan besaran R yaitu 0,543. Hal ini berarti terdapat korelasi antara X3 dan Y. Koefisien determinasi $\left(\mathrm{R}^{2}\right)$ sebesar 0,294 menunjukkan bahwa X3 berpengaruh terhadap $\mathrm{Y}$ 
sekuat 29,4\%. Artinya, budaya sekolah berpengaruh terhadap kinerja guru sebesar 29,5\%. Analisis persamaan regresi antara X3 dan Y disajikan berikut ini.

$$
\hat{Y}=36,183+0,543 X_{3}
$$

Persamaan regresi ini memiliki makna yaitu koefisien regresi atau nilai b sebesar 0,543. Artinya yaitu kenaikan satu skor budaya sekolah akan meningkatkan skor kinerja guru sebesar 0,543. Ini juga berarti semakin bertambah nilai budaya sekolah $\left(\mathrm{X}_{1}\right)$, maka semakin bertambah pula nilai kinerja guru $(\mathrm{Y})$.

\subsection{Pengaruh kepemimpinan kepala sekolah, supervisi pendidikan, dan budaya sekolah terhadap kinerja guru}

Uji hipotesis keempat menggunakan regresi ganda antar variabel kepemimpinan kepala sekolah (X1), supervisi pendidikan (X2), dan budaya sekolah (X3) dengan kinerja guru (Y). Hipotesisnya (Ha) yaitu kepemimpinan kepala sekolah,supervisi pendidikan, dan budaya sekolah secara bersama-sama berpengaruh terhadap kinerja guru. Kriteria yang digunakan adalah Ha diterima jika nilai sign $<0,05$. Hasil uji signifikasi dengan SPSS 23 dapat dilihat pada Tabel 9.

Tabe19. Hasil uji regresi linier X1, X2, dan X3 terhadap Y

\begin{tabular}{clc}
\hline $\mathbf{R}$ & R Square & Adjusted R Square \\
\hline 0,684 & 0,468 & 0,457 \\
\hline
\end{tabular}

Tabel 9 menunjukkan koefisien determinasi $\left(\mathrm{R}^{2}\right)$ sebesar 0,684 dan nilai adjust $\mathrm{R}^{2}$ sebesar 0,457. Terdapat tiga variabel bebas pada hipotesis keempat. Oleh karena itu, koefisien determinasi yang digunakan adalah adjust $\mathrm{R}^{2}$. Ketiga varibel bebas secara bersama-sama berpengaruh terhadap Y sebesar 45,7\%. Artinya, kepemimpinan kepala sekolah, supervisi sekolah dan budaya sekolah secara bersama-sama berpengaruh terhadap kinerja guru sebesar 45,7\%. Analisis persamaan regresi X1, X2, dan X3 dengan Y disajikan berikut ini.

$$
\hat{Y}=24,618+0,427 X_{1}+0,044 X_{2}+0,3698 X_{3} \text {. }
$$

Persamaan regresi tersebut memiliki makna yaitu semakin besar nilai kemimpinan kepala sekolah,supervisi pendidikan dan budaya sekolah, maka semakin besar nilai kinerja guru.

\section{PEMBAHASAN}

\subsection{Pengaruh kepemimpinan kepala sekolah terhadap kinerja guru}

Kepala sekolah berperan sebagai tokoh sentral dalam penyelenggaraan pendidikan dan pembelajaran di sekolah. Ada banyak peran yang dijalankan oleh kepala sekolah yakni sebagai 
administrator, manajer, dan supervisor. Kepala sekolah sebagai supervisor memiliki peran utama untuk mengembangkan komunitas profesional para guru yang akan berdampak pada kinerja pembelajarannya. Penelitian ini membuktikan bahwa terdapat pengaruh kepemimpinan kepala sekolah terhadap kinerja guru dengan signifikansi uji regresi (p) sebesar 0,000 (p < 0,05). Dengan demikian, kepemimpinan kepala sekolah berpengaruh pada kinerja guru. Hasil penelitian ini selaras dengan berbagai hasil penelitian sebelumnya bahwa kepemimpian memiliki dampak secara tidak langsung (Dixon, 2015, Larsen, dkk, 2015, Derrington \& Lomascolo, 2015) maupun langsung terhadap kinerja (Larsen, dkk, 2015, Wagner \& Wagner, 2015. Hasil penelitian juga menunjukkan koefisien determinasi sebesar 0,350. Artinya pengaruh kepemimpinan kepala sekolah terhadap kinerja guru di sekolah dasar negeri di Kecamatan Kajoran, Kabupaten Magelang sebesar 35\%. Sisanya sebesar 65\% dipengaruhi oleh faktor lain.

Hasil penelitian ini menegaskan bahwa semakin bertambah nilai $X_{1}$ semakin bertambah pula pada nilai Y. Oleh karena itu dapat dimaknai bahwa semakin bertambah nilai kepemimpinan kepala sekolah $\left(\mathrm{X}_{1}\right)$, maka semakin bertambah pula nilai kinerja guru $(\mathrm{Y})$. Dengan kata lain semakin bertambah kualitas kepemimpinan kepala sekolah, semakin meningkatkan kinerja guru. Beberapa penelitian menunjukan bahwa kepemimpinan kepala sekolah menjadi motivator peningkatan kinerja guru (Tambigon, 2018 dan Chen, 2017). Dari berbagai gaya atau pendekatan kepemimpinan yang diterapkan kepala sekolah, semuanya memiliki peran signifikan terhadap perubahan atau dinamika kinerja guru. Hartini (2019) menyatakan dalam penelitiannya bahwa gaya kepemimpinan kepala sekolah memiliki pengaruh positif dan signifikan terhadap kinerja guru. Namun di sisi lain, ada hal yang cukup menarik jika dibandingkan dengan hasil temuan Nasra dan Arar (2019) yang menyatakan bahwa gaya kepemimpinan kepala sekolah memiliki pengaruh tidak langsung terhadap kinerja guru. Hal ini mengindikasikan kebutuhan penelitian lebih lanjut untuk mengetahui seberapa jauh pengaruh langsung atau tidak langsung kepemimpinan kepala sekolah terhadap kinerja guru.

\subsection{Pengaruh supervisi pendidikan terhadap kinerja guru}

Supervisi merupakan upaya profesional yang diberikan kepala sekolah kepada guru untuk mengembangkan profesinya. Kepala sekolah berperan sebagai supervisor struktural dalam menjalan tugas supervisorship. Falender dan Shafranske (2004) menjelaskan bahwa supervisi memiliki peran yang signifikan terhadap kinerja guru. Hasil penelitian ini menguatkan 
pandangan tersebut.supervisi pendidikan berpengaruh terhadap kinerja guru. Hasil koefisien determinasi sebesar 0,130 menunjukkan pengaruh supervisi pendidikan terhadap kinerja guru di sekolah dasar negeri di Kecamatan Kajoran, Kabupaten Magelang sebesar 13\%. Sisanya sebesar $87 \%$ dipengaruhi oleh faktor lain.

Hasil penelitian ini menegaskan bahwa semakin bertambah nilai $\mathrm{X}_{2}$ semakin bertambah pula nilai $Y$. Oleh karena itu, semakin bertambah nilaisupervisi pendidikan $\left(\mathrm{X}_{2}\right)$, semakin bertambah pula nilai pada kinerja guru (Y). Supervisi merupakan upaya profesional dari seorang pengawas dalam memperbaiki situasi pembelajaran yang diselenggarakan guru. Semakin intens dan berkualitas supervisi, kinerja guru akan semakin baik (Ampofo, 2019, Darishah, Daud, \& Omar-fauzee, 2017).

\subsection{Pengaruh budaya sekolah terhadap kinerja guru}

Kinerja seorang guru akan ditentukan oleh banyak aspek baik internal maupun eksternal. Dari sisi internal, aspek budaya memiliki peran yang signifikan terhadap kinerja mereka. Nilai-nilai dan keyakinan yang diemban seorang guru akan menentukan kinerjanya termasuk nilai dan budaya yang diterapkan oleh lembaga sebagai faktor eksternal. Budaya diterjemahkan sebagai norma, nilai dan interaksi yang terjadi di lembaga yang memiliki peran penting dalam pencapaian tujuan lembaga (Hoy, W.K., Tarter, C.J., dan Kottkamp, R.B, 1991). Hasil penelitian ini membuktikan bahwa terdapat pengaruh budaya sekolah terhadap kinerja guru dengan signifikansi uji regresi (p) sebesar 0,000 ( $\mathrm{p}<0,05)$. Dengan demikian terdapat pengaruh budaya sekolah terhadap kinerja guru. Koefisien determinasi menunjukkan hasil sebesar 0,294 atau pada kategori lemah. Ini menunjukkan pengaruh budaya sekolah terhadap kinerja guru di sekolah dasar negeri di Kecamatan Kajoran, Kabupaten Magelang sebesar $29,4 \%$, sedangkan sisanya sebesar 70,6\% dipengaruhi oleh faktor lain.

Hasil penelitian ini menegaskan bahwa semakin besar nilai budaya sekolah $\left(\mathrm{X}_{3}\right)$, maka semakin besar nilai kinerja guru (Y). Dengan kata lain semakin bertambah baik budaya sekolah, maka semakin meningkat kinerja guru. Jika ditelusuri, budaya sekolah yang positif pada praktiknya akan menumbuhkan kepuasan kerja para guru (Duan \& Du, 2018, Morris \& Bloom, 2002). 


\subsection{Pengaruh kepemimpinan kepala sekolah,supervisi pendidikan dan budaya sekolah terhadap kinerja guru}

Kinerja guru banyak dipengaruhi oleh faktor internal dan eksternal. Faktor internal dan eksternal ini selaras dengan pandangan Fidler dan Atton (1999). Mereka menyebutkan empat determinan kinerja guru, yaitu a) pekerjaan dan konteksnya; b) manajemen guru yang diterapkan sekolah; c) proses seleksi dan penugasannya; dan 3) kualitas personal. Hasil penelitian ini membuktikan bahwa terdapat pengaruh variabel kepemimpinan kepala sekolah,supervisi pendidikan, dan budaya sekolah terhadapkinerja guru. Koefisien determinasi menunjukkan bahwa terdapat pengaruh variabel kepemimpinan kepala sekolah, supervisi pendidikan, dan budaya sekolah secara bersama-sama dalam meningkatkan kinerja guru .

Hal ini membuktikan bahwa kepemimpinan kepala sekolah, supervisi pendidikan, dan budaya sekolah mampu memberikan pengaruh yang positif terhadapkinerja guru sekolah dasar negeri di Kecamatan Kajoran Kabupaten Magelang. Yamin \& Maisah (2010) menjelaskan bahwa faktor kinerja guru tidak hanya kepemimpinan,supervisi pendidikan, dan budaya sekolah namun juga faktor lain seperti personal atau individu, tim, sistem, dan kontekstual. Berdasarkan hasil penelitian ini ditemukan bahwa semakin bertambah kualitas pengaruh variabel kepemimpinan kepala sekolah, supervisi pendidikan, dan budaya sekolah maka akan semakin meningkat kinerja guru.

\section{V.SIMPULAN}

Hasil penelitian menyimpulkan bahwa: (1) terdapat pengaruh kepemimpinan kepala sekolah terhadap kinerja guru sekolah dasar negeri di Kecamatan Kajoran Kabupaten Magelang sebesar $35 \%$; (2) terdapat pengaruhsupervisi pendidikan terhadap kinerja guru sekolah dasar negeri di Kecamatan Kajoran Kabupaten Magelang sebesar 13\%; (3) terdapat pengaruh budaya sekolah terhadap kinerja guru sekolah dasar negeri di Kecamatan Kajoran Kabupaten Magelang sebesar $29,4 \%$; (4) terdapat pengaruh kepemimpinan kepala sekolah, supervisi pendidikan, dan budaya sekolah secara bersama-sama terhadap kinerja guru sebesar $45,7 \%$.

Penelitian ini menyarankan beberapa hal kepada berbagai pihak. (1) Guru hendaknya secara terus menerus dan berkesinambungan meningkatkan kualitas diri dengan meningkatkan kompetensi dan kinerja diri sehingga tujuan pendidikan dapat tercapai. (2) Kepala sekolah hendaknya memahami tugas, peran dan fungsinya dalam upaya menigkatkan kinerja guru. (3) Supervisi perlu ditingkatkan di sekolah secara kontinyu untuk meningkatkan kinerja guru serta memajukan pendidikan. (4) Pemerintah perlu melakukan inovasi untuk meningkatkan kualitas 
sekolah, kepala sekolah, dan guru agar interaksi antar ketiganya dapat berjalan dengan baik dan mampu menghasilkan pendidikan yang berkualitas.

\section{Acknowledgement}

Penulis ucapkan terima kasih kepada seluruh pihak yang telah membantu penelitian ini, khsusunya kepada Universitas Negeri Yogyakarta dan SDN Kajoran 2 Magelang.

\section{DAFTAR PUSTAKA}

Abu Nasra, Muhammed \& Arar, Khalid. (2019). Leadership style and teacher performance: mediating role of occupational perception. International Journal of Educational Management. ahead-of-print. 10.1108/IJEM-04-2019-0146.

Ampofo. (2019). Influence of school heads' direct supervision on teacher role performance in public senior high schools, Central Region, Ghana. IAFOR Journal of Education, 7(2), 9-26.

Chen,Yi-Gean. (2017). Exploring differences from principal's leadership and teacher'steaching performances in public and private schools. The Journal of International Management Studies, 12(2), 65-81.

Darishah, P., Daud, Y., \& Omar-fauzee, M. (2017). Teaching and learning supervision by school management, attitude of teacher and competency of teaching. International Journal of Development and Sustainability, 6(10), 1367-1381.

Darling-Hammond, L. (2000). Teacher quality and student achievement: A review of state policy evidence. Education Policy Analysis Archives, 8(1), 1-44.

Deal, T. E., \& Peterson, K. D. (1999). Shaping school culture: The heart of leadership. San Francisco: Jossey-Bass inc.

Derrinton, M.L. \& Lomascolo, D. J. (2015). Principal support of teachers and its impact on student achievement. DiPaola, M.F. \& Hoy, W.K. (ed) Leadership and Quality. Charlotte: Information Ages Publishing, Inc.

Dixon, L.D. (2015) Servant leadership and organizational citizenship behavior: Predictors of climate. DiPaola, M.F. \& Hoy, W.K. (ed) Leadership and Quality. Charlotte: Information Ages Publishing, Inc.

Duan, X. \& Du, X. (2018). School culture and school effectiveness: The mediating effect of teacher's job satisfaction. International Journal of Learning, Teaching and Educational Research, 17(5), 15-25.

Falender, C.A., Shafranske, E.P. (2004). Clinical supervision, A competency-based approach. Washington DC: American Psychological Association.

Fajriah. (2017). Learing journal: Improving teaching strategies through student's reflections. Sukma: Jurnal Pendidikan, 1(2). 301-327.

Fidler, B. and Atton, T. (1999). Poorly performing staff in school and how to manage them. London: Routledge. 
Hartini, S.R. (2019). Pengaruh gaya kepemimpinan kepala sekolah terhadap kinerja guru di SMPN 3 Marioriwawo Kabupaten Soppeng. Thesis. Makassar: Universitas Negeri Makassar.

Hoy, W.K., Tarter, C.J., Kottkamp, R.B. (1991). Open schools, healthy schools: Measuring organizational climate. California: Sage Publication.

Jasmin \& Mustofa. (2013). Supervisi pendidikan. Yogyakarta: Ar-rus media.

Larsen, R.A.A, et.al. (2015). Direct and indirect effects of principal leadership on teacher quality and mathematics achievement in the context of the responsive classroom approach. DiPaola, M.F. \& Hoy, W.K. (ed) Leadership and Quality. Charlotte: Information Ages Publishing, Inc.

Latief, S. (2016). pengaruh supervisi akademik kepala sekolahdan kompetensipedagogik guru terhadap kinerja guru sekolah dasar negeri gugus Sikapat dan Sipayung Kecamatan Kajoran Kabupaten Magelang. Thesis, Semarang: Universitas Negeri Semarang.

Mammaova, S. (2019). Teacher quality v s. teaching quality. Azerbaijan Journal of Educational Studies, 686(I), 25-32.

Mangkunegara A. A. A. P. (2009). Manajemen sumber daya manusia. Bandung. PT. Rosda Karya.

Menteri. (2007). Permendiknas No.13 Tahun2007tentang Standar Kepala Sekolah/Madrasah

Morris, A. \& Bloom, J.R. (2002). Contextual factors affecting job satisfaction and organizational commitment in community mental health centers undergoing system changes in the financing of care. Mental Health Services Research, 4(2), 71-83.

Nasriyah, S. (2014). Media cerita bergambar untuk meningkatkan kemampuan membaca pada anak usia dini kelompok B raudlatul athfal masyithah Madugondo Kajoran Kabupaten Magelang Jawa Tengah Tahun Pelajaran 2013/2014. Skripsi: Yogyakarta: UIN Sunan Kalijaga.

Oktradiksa, A \& Nugroho, I. (2015). Peran kepala madrasah ibtidaiy ah muhammadiyah dalam membentuk keunggulan menuju madrasah unggulan Magelang. The 2nd University Research Coloquium 2015.

Purwanto. (2009). Adminitrasi dan supervisi pendidikan. Bandung: Remaja Rosdakarya.

Sagala, S. (2013). Kemampuan professional guru dan tenaga pendidikan. Bandung: Alfabeta.

Supraswati, I. (2016). Hubungan antara motivasi berprestasi dengan kinerja guru dalam pembelajaran sdn gugus Silawe Kajoran Magelang. Jurnal Pendidikan Sekolah Dasar, 14(5), 143-352.

Sugiyono. (2010). Metode Penelitian kuantitatif kualitatif dan $r \& d$. Bandung: Alfabeta.

Tambigon, H.N. (2018). The influence of principal leadership style and teacher work motivation on the performance of certified teacher at SMA Negeri Kotamobago, North Sulawesi. Journal of Education and Learning (EduLearn ), 12(3), 357-365.

Wahjosumidjo (2010) Kepemimpinan kepala sekolah. Jakarta: Rajadrafindo Persada.

Wagner, K.E. \& Wagner, C.A. (2015). Instructional leadership behaviors: The impact on teachers' classroom instruction. DiPaola, M.F. \& Hoy, W.K. (ed) Leadership and Quality. Charlotte: Information Ages Publishing, Inc.

Wibowo. (2011). Manajemen kinerja. Jakarta: Raja Grafindo Persada. 
Wirawan (2008). Budaya dan iklim organisasi: Teoriaplikasidan penelitian. Jakarta: Salemba Empat.

Wirawan. (2013). Kepemimpinan. Jakarta: Karisma Utama Offset.

Yamin \& Maisah. (2010). Kepemimpinan dan manajemen masa depan. Bogor: IPB Press. 